\title{
Trial of sustained-release tetracycline in the treatment of gonorrhoea
}

\author{
P. S. SILVER \\ Medical Director, Diagnostic Clinic, Health Department, Civic Centre, Bolton, Lancs.
}

It has been suggested (Neumann and Baecker, 1972) that penicillin should be considered too valuable a drug to be used injudiciously for a disease as widespread and as likely to recur as gonorrhoea, and that it should be reserved for syphilis, gonorrhoeal complications, and treatment during pregnancy. It was further suggested that it was preferable to use other broad spectrum antibiotics in cases of uncomplicated gonorrhoea because of:

(1) The steady increase in sensitivity reactions to penicillin;

(2) The existing cross-allergenicity of the penicillins and the cephalosporins;

(3) The resurgence of syphilis and the problem of having to treat it without the benefit of penicillin in patients who have become sensitized.

A further point to note is the increasing resistance of the gonococcus to penicillin as evidenced by laboratory examination of cultures.

The search for alternatives to penicillin has been extensive. Some of the agents that have been tried, such as chloramphenicol or kanamycin, are potentially too toxic for routine use, and the usefulness of the cephalosporins is limited by their crossallergenicity with the penicillins.

Tetracycline and its derivatives have been found to be effective in the treatment of uncomplicated gonorrhoea in both sexes (Neumann and Baecker 1972; Masterton and Schofield, 1972; Moffett, McGill, Masterton, and Schofield, 1972; Kloosman, 1972). This report is of a clinical trial of Sustamycin, a sustained-release preparation of tetracycline hydrochloride, in this condition. The tetracycline is presented in the form of granules which are so formulated that, after partial absorption in the stomach, absorption will continue in the high $\mathrm{pH}$ of the small intestine. This is achieved by creating a local acid environment at the point of release, thus providing

Received for publication April 22, 1974 favourable conditions for absorption. The result is that only half of the dosage of conventional tetracycline is needed. The preparation has been shown to be effective in a variety of clinical conditions and plasma levels appear to be adequate (Knapp, 1966; Hooper, 1970). As a result of the more complete absorption, it is possible that the occurrence of irritant side-effects in the bowel is reduced. An advantage of Sustamycin over most other tetracyclines is the twelve-hourly dosage; it is more likely that patients will remember to take a capsule only twice daily.

\section{Material and methods}

Sixty male patients were included in the study. Their ages ranged from 18 to 55 years, 78 per cent. of them being in the range 18 to 30 years. The time which had elapsed between exposure to infection and start of treatment varied from 3 days to 3 weeks, with the exception of two patients, one of whom had been exposed probably 9 weeks before and the other admitted only to regular intramarital intercourse. Initial diagnosis was made by means of Gram-stained smears taken from the urethra. The diagnosis was confirmed by cultures of material obtained by swabs and sent to the laboratory in Amies transport medium (Difco). On arrival at the laboratory they were plated on lysed blood agar (Oxoid Blood Agar Base No. 2 with 10 per cent. lysed defibrinated horse blood added) and lysed blood agar with trimethoprim lactate $5 \mu \mathrm{g} . / \mathrm{ml}$., vancomycin hydrochloride $3 \mu \mathrm{g} . / \mathrm{ml}$., and polymyxin B sulphate $20 \mu \mathrm{g} . / \mathrm{ml}$. added. The plates were then incubated at $37^{\circ} \mathrm{C}$. in a carbon dioxide-air atmosphere and examined after 24 and $48 \mathrm{hrs}$. The same atmosphere was used for all subsequent tests. Gram-staining was carried out on films from suspicious oxidase-positive colonies and a presumptive report was issued if the organisms were morphologically typical of $N$. gonorrhoeae.

A presumptive positive colony was subcultured on lysed blood agar to obtain adequate 18-hr growth for sugar fermentation tests and sensitivity tests. Fermentation tests were carried out using a heavy inoculum on serumfree sugars (Flynn and Waitkins, 1972) and the results were read after $48 \mathrm{hrs}$ ' incubation. For sensitivity tests two or three colonies were spread evenly on a lysed blood agar plate and the following discs were applied: pencillin 
1 unit, streptomycin $10 \mu \mathrm{g}$, and tetracycline $10 \mu \mathrm{g}$. The plates were incubated for $18 \mathrm{hrs}$ without prediffusion, and the zones of inhibition were then measured and interpreted as follows:

\begin{tabular}{|c|c|c|c|}
\hline Antibiotic & Sensitive & $\begin{array}{l}\text { Less } \\
\text { sensitive }\end{array}$ & $\begin{array}{l}\text { Relatively } \\
\text { resistant }\end{array}$ \\
\hline Penicillin & $27 \mathrm{~mm}$. or more & $20-26 \mathrm{~mm}$ & $\begin{array}{l}\text { Less than } \\
20 \mathrm{~mm} \text {. }\end{array}$ \\
\hline Tetracycline & $21 \mathrm{~mm}$. or more & $\begin{array}{l}\text { Less than } \\
21 \mathrm{~mm} \text {. }\end{array}$ & \\
\hline Streptomycin & $15-20 \mathrm{~mm}$. & & \\
\hline
\end{tabular}

In every case treatment with the Sustamycin was started immediately, the dosage being $500 \mathrm{mg}$. (two capsules) initially followed by $250 \mathrm{mg}$. twice daily for 5 days.

Patients were examined between 4 and 9 days after starting treatment, and where possible, at regular intervals up to 3 months after treatment. All patients included in the trial were examined at least twice after starting treatment. A Gram-stained smear and a urine sample were examined at each visit and at least one culture carried out after the period of treatment. Serological tests for syphilis were done before and after treatment in each case where the patient did not default.

\section{Results}

Three patients defaulted without follow-up examinations being carried out and are therefore excluded from the trial. Of the 57 remaining, 54 were examined within 9 days of starting treatment and then at least once more during the subsequent 3 months. The duration of follow-up varied from 2 to 17 weeks.

Of the infecting organisms, 48 were successfully cultured. The sensitivities and results obtained are set out in the Table. In all cases the blood tests for syphilis were negative.

\section{Definition of cure}

Complete absence of discharge, clear urine, and a negative culture for a minimum of 3 weeks after treatment.

\section{Definition of failure}

Patients with persisting discharge containing gonococci.

\section{Definition of relapse}

Patients with recurrences whose original discharge cleared but returned within 14 days, with no history of fresh exposure.

\section{Definition of re-infection}

Patients with recurrences whose original discharge cleared but who admitted re-exposure and whose contacts were found to be suffering from gonorrhoea.

The total number of patients cured of gonorrhoea was 47 ( 82.5 per cent. of those completing the trial). There were eight failures and two relapses. Of the eight failures, one had congenital hypospadias and in four other cases re-infection was a strong possibility, although no proof could be obtained.

Of the two relapses, one patient had hypospadias with a blind sinus. Of the 47 cured, seven (12 per cent.) developed non-specific urethritis. No patient complained of any side-effects at any time during the trial.

\section{Discussion}

The results in this series with the sustained release preparation are as good as those obtained with our standard treatment with tetracycline $(500 \mathrm{mg}$. 8-hrly

\section{TABLE Results related to sensitivity of gonococcus}

\begin{tabular}{|c|c|c|c|c|c|c|}
\hline \multirow{2}{*}{\multicolumn{2}{|c|}{ Sensitivity group }} & \multirow[b]{2}{*}{ No. of cultures } & \multicolumn{4}{|c|}{ Results with Sustamycin } \\
\hline & & & \multirow{2}{*}{$\begin{array}{l}\text { Cures } \\
23\end{array}$} & \multirow{2}{*}{$\begin{array}{l}\text { Failures } \\
1\end{array}$} & \multirow[t]{2}{*}{ Relapses } & \multirow{2}{*}{$\frac{\text { Defaulter }}{1}$} \\
\hline (1) & $\begin{array}{l}\text { Sensitive to tetracycline } \\
\text { Sensitive to penicillin } \\
\text { Sensitive to streptomycin }\end{array}$ & 25 & & & & \\
\hline (2) & $\begin{array}{l}\text { Sensitive to tetracycline } \\
\text { Sensitive to streptomycin } \\
\text { Less sensitive to penicillin }\end{array}$ & 10 & 9 & & 1 & \\
\hline (3) & $\begin{array}{l}\text { Sensitive to tetracycline } \\
\text { Sensitive to streptomycin } \\
\text { Relatively resistant to penicillin }\end{array}$ & 3 & 3 & & & \\
\hline (4) & $\begin{array}{l}\text { Sensitive to tetracycline } \\
\text { Relatively resistant to penicillin } \\
\text { Relatively resistant to streptomycin }\end{array}$ & 8 & 3 & 4 & 1 & \\
\hline (5) & $\begin{array}{l}\text { Less sensitive to tetracycline } \\
\text { Less sensitive or relatively resistant to penicillin } \\
\text { Resistant to streptomycin }\end{array}$ & 2 & & 2 & & \\
\hline
\end{tabular}

Of the twelve cases in which the organism could not be cultured, the results were: 9 Cures; 1 Failure; 2 Defaulters 
for 5 days). The incidence of post-gonococcal urethritis was, in our experience, similar to that which occurred after any other method of treatment. It is worth noting that three of the patients who were cured had congenital hypospadias and that one of the relapses and one of the failures also had this condition. Such patients tend to relapse more frequently.

The main advantage of this preparation is the 12-hrly dosage. This regimen should assist the patient to remember to take the prescribed dose. This is an important point when the success of treatment depends on the patient taking the treatment reliably for the prescribed number of days. The results in this trial indicate that this was done by most patients, but it should be remembered that male gonorrhoea patients are particularly prone to saving a few capsules 'for the next time'. Examination of the strains in this series of patients in vitro indicated a relative resistance to penicillin in 25 per cent. of the successful cultures. Only two cultures were 'less sensitive' to tetracycline, and these patients were two of the eight failures. The changing pattern of resistance to penicillin, the increasing occurrence of sensitivity reactions, and the existence of cross-allergenicity with the cephalosporins may all be considered as reasons to use an alternative broad spectrum agent in the treatment of uncomplicated gonorrhoea.

The tetracyclines have proved to be an effective alternative in this clinic while providing a safe and economic form of therapy. The Sustamycin formulation provides tetracycline hydrochloride in a form which is more likely to be reliably taken by the patient than a course of conventional tetracycline therapy. In addition, the more complete absorption achieved with this formulation should minimize the risk of irritant side-effects on the bowel.

\section{Summary}

A trial of Sustamycin, a sustained-release preparation of tetracycline hydrochloride, in uncomplicated gonorrhoea in sixty males is described. Each patient was given an initial dose of $500 \mathrm{mg}$. followed by $250 \mathrm{mg}$. twice daily for 5 days. Of the 57 patients who attended for follow-up 47 ( 82.5 per cent.) were cured.

There were no adverse reactions.

\section{References}

Flynn, J., and Waitkins, S. A. (1972) f. clin. Path., 25, 525

Hooper, A. C. (University College, Dublin) (1970) Unpublished report.

Kloosmann, W. L. S. (1972) S. Afr. med. F., 46, 584

KNAPP, J. E. (1966) Unpublished report of a clinical trial in general practice, Toronto, Canada

Masterton, G., and Schofield, C. B. S. (1972) Brit. $\mathcal{F}$. vener. Dis., 48, 121

Moffett, M., MCGill, M. I., Masterton, G., and SCHOFIELD, C. B. S. Ibid., 48, 126

Neumann, H. H., and BaECKer, J. M. (1972) F. Amer. med. Ass., 219, 471 